Doctrina

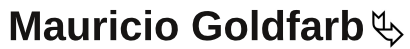

\section{Silencio de la administración en los derechos uruguayo y argentino}

\section{Silence of the Administration in the Uruguayan and Argentine law \\ Silêncio da administração nos direitos uruguaio e argentino}

Resumen: El silencio de la administración es un instituto del Derecho Administrativo en el que a la falta de respuesta del ente público se le asigna un significado, por lo general desestimatorio. Los sistemas administrativos uruguayo y argentino poseen importantes similitudes y algunas diferencias en su regulación. En este artículo se comparan críticamente ambos sistemas y se exponen sus diferencias y puntos en común.

Palabras clave: función administrativa, acto administrativo, organización administrativa, eficacia, plazo razonable.

Abstract: The silence of the administration is an institute of Administrative Law in which at the absence of a response from the public entity is assigned a meaning, usually dismissing the petition. The Uruguayan and argentine administrative systems have important similarities and some differences in their regulation. In this paper, both systems are compared, pointing their differences and points in common.

Keywords: administrative function, administrative act, administrative organization, effectiveness, reasonable time.

Resumo: O silêncio da administração é um instituto de Direito Administrativo no qual a falta de resposta da entidade pública recebe um significado, geralmente depreciativo. Os sistemas administrativos uruguaio e argentino têm importantes semelhanças e algumas diferenças em sua regulamentação. Neste artigo, os dois sistemas são comparados criticamente e suas diferenças e pontos em comum são expostos.

$\stackrel{4}{\rightarrow}$ Universidad Nacional del Nordeste (Argentina). Abogado, Especialista en Derecho Administrativo, Doctor en Derecho. Orcid: 0000-0002-9152-7638

estudiogoldfarb@hotmail.com 
Palavras-chave: função administrativa, ato administrativo, organização administrativa, eficácia, tempo razoável.

Recibido: 20200628

Aceptado: 20200902 


\section{Introducción}

El presente trabajo de investigación tiene como objetivo la comparación crítica de los sistemas uruguayo y argentino en relación al silencio de la Administración. El tema de la inactividad formal de los entes públicos posee relevancia ya que, la experiencia demuestra que uno de los mayores defectos del procedimiento administrativo ha sido siempre la cuestión del excesivo tiempo de resolución. Esta demora injustificada en resolver las peticiones de los particulares es violatoria del derecho a la tutela efectiva de los administrados y afecta además el principio de eficiencia que debe gobernar todo el accionar estatal. En este marco, el silencio administrativo es - desde antaño - un instituto valioso, que funciona como una vía de protección y tutela del ciudadano ante la inactividad de los entes estatales.

Para realizar este trabajo de investigación se han utilizado herramientas metodológicas del derecho comparado, con referencias a la doctrina y a la jurisprudencia uruguaya y argentina. Todo estudio de derecho comparado exige definir las variables que se tomarán en cuenta, ya que la mera yuxtaposición de normas (a pesar de su origen común y sus múltiples aspectos coincidentes) sería una tarea extensa y poco útil. Por ello, en este estudio se consideran y comparan críticamente ambos sistemas jurídicos desde tres tópicos: La jerarquía normativa del deber de resolver las peticiones, las consecuencias jurídicas del silencio y las excepciones a la regla. Estos aspectos son abordados desde una perspectiva cualitativa y teórica, pero no desligados de la realidad, sino en conexión directa con su efectiva realización. En la revisión del marco teórico, no existen estudios publicados que comparen ambos sistemas, ni que expongan sus ventajas y desventajas. En las conclusiones se expone la valoración crítica de cada ordenamiento, partiendo siempre desde la tutela efectiva de los derechos del ciudadano. 


\section{Procedimiento administrativo y derecho a peticionar a las autoridades}

El procedimiento administrativo es la manera en la que se expresa jurídicamente la función administrativa. El trámite puede tener origen en una iniciativa de la propia Administración o de un particular. Cuando se trata de la petición de un particular, nos encontramos con un instituto de larga tradición en el derecho público: El derecho de peticionar a las autoridades. Peticionar es el derecho de reclamar, demandar o solicitar a los órganos con función administrativa una conducta u omisión concreta. Se trata de la facultad de dirigirse a los poderes públicos y tiene como correlato, el deber de la Administración de dar respuesta cierta y oportuna a tales peticiones (Gelli, 2008). Este derecho de peticionar tiene sus orígenes más remotos en el Bill of Rights inglés de 1689, la Constitución francesa de 1791 y la I Enmienda de la Constitución de los Estados Unidos de América. En el caso de nuestras dos unidades de análisis, el derecho a peticionar se halla expresamente reconocido en la Constitución de la República Oriental del Uruguay en el artículo 30(1), y en la República Argentina en el artículo 18 de la Constitución Nacional ${ }^{(2)}$.

Por tratarse de un derecho humano fundamental, la Administración no puede ampararse válidamente en su mera inactividad o en el silencio para sostener que ha resuelto la petición o la cuestión planteada de un modo tácito o presunto. Por el contrario, como regla, el procedimiento debe concluir con una respuesta expresa a las peticiones de los ciudadanos (Gordillo A. D., 2010, pág. 33). Como corolario, si es un deber del órgano con función administrativa el impulso del trámite y la conclusión con una decisión expresa, el silencio y la inactividad ante la petición de los ciudadanos son antijurídicos y pueden acarrear responsabilidad (civil, penal, administrativa, según el caso) para los incumplidores.

\section{Silencio administrativo}

Cuando un particular se presenta y formula una pretensión ante la Administración debería obtener una respuesta expresa (sea positiva o negativa) y en un plazo razonable, a través del dictado del acto administrativo correspondiente. Pero la realidad nos enseña que, muchas veces, los órganos administrativos encargados de tramitar esta petición no brindan una respuesta expresa o no lo hacen de modo oportuno.

Como uno de los modos de mitigar este vicio común de las administraciones, los ordenamientos jurídicos han creado desde antaño el instituto del silencio administrativo. Este instituto era, en cierto modo, derivación del dogma revisor del con- 
tencioso administrativo: Los jueces solo podían resolver respecto de la validez de los actos de la Administración (Perrino, 2003). En consecuencia, se creaba una ficción, en la que la ley establecía que se consideraba la solicitud del interesado como estimada (silencio positivo) o desestimada (silencio negativo) cuando la Administración incumplía el deber que tiene de resolver de modo expreso (Lima, 2009). La doctrina administrativista clásica, de manera congruente con la concepción del contencioso administrativo como un juicio al acto, consideraba al silencio como un verdadero acto (tácito, ficticio o presunto) denegatorio, que luego sería revisado en sede judicial. La superación del dogma revisor, y la aceptación de una revisión amplia de la actividad (y la inactividad) de la Administración y su compatibilidad con todo el orden jurídico, hace innecesaria recurrir a tales ficciones. Es más, la inactividad administrativa que resulta en el silencio implica, justamente, la ausencia de un acto (Tenreyro, 2011, pág. 166).

El silencio administrativo es, entonces, una técnica de tutela que el ordenamiento jurídico brinda al ciudadano frente a la inactividad o la falta de repuesta dentro del procedimiento (Nieto García, 1962). El silencio ha sido definido en España como la ficción jurídica por la que se entiende, en defensa de los derechos del administrado, que se ha dictado una resolución de carácter estimatoria o desestimatoria, según el caso, cuando transcurren los plazos máximos que tiene la Administración para resolver un procedimiento y notificar la resolución de la misma, sin que se cumpla con dichas obligaciones (Rodríguez Arana, 2009, págs. 210, Tomo II).

Como veremos más adelante, Uruguay y Argentina comparten el principio del silencio como desestimatorio (salvo norma expresa en contrario). Este sistema tiene una ventaja importante: su sencillez y claridad. El particular sabe que, ante la falta de respuesta oportuna, el sentido de la omisión estatal es denegatorio, sin que por ello la omisión pierda su carácter antijurídico.

Por otra parte, no es menos cierto que este sistema alienta — de un modo indirecto- la falta de resolución de las peticiones. El funcionario tiene un camino sencillo y poco comprometido: si no resuelve la petición, esta se considera desestimada y nadie puede imputarle connivencia ni apresuramiento al resolver. Si algún derecho ha sido desconocido en el camino, allí está el órgano jurisdiccional para repararlo. Este modo de razonar — muy común en los funcionarios- es claramente antijurídico, porque, como ya vimos, viola el principio de tutela efectiva que exige que las peticiones tengan respuesta expresa y oportuna. 


\section{El sistema uruguayo}

La Constitución uruguaya contiene una sección entera dedicada a la cuestión administrativa. En 15 artículos (del 307 al 321) repartidos en tres capítulos se regula el tema con gran detalle, algo inusual para una norma constitucional (Cajarville Peluffo, 2014). Estas normas constitucionales tienen su origen en la Constitución aprobada en 1952, y se han mantenido no obstante las reformas posteriores del texto constitucional. En la Constitución se establece la creación de un órgano extra poder: El Tribunal Contencioso Administrativo, con competencia para entender en los procesos de anulación de los actos administrativos. También se regulan las facultades del tribunal, su integración y sus potestades solo anulatorias y no reparatorias ${ }^{(3)}$.

La Constitución uruguaya establece el principio de la recurribilidad administrativa y judicial de los actos administrativos:

Artículo 317.- Los actos administrativos pueden ser impugnados con el recurso de revocación, ante la misma autoridad que los haya cumplido, dentro del término de diez días, a contar del día siguiente de su notificación personal, si correspondiere, o de su publicación en el "Diario Oficial”.

Cuando el acto administrativo haya sido cumplido por una autoridad sometida a jerarquías, podrá ser impugnado, además, con el recurso jerárquico, el que deberá interponerse conjuntamente y en forma subsidiaria, al recurso de revocación.

Cuando el acto administrativo provenga de una autoridad que según su estatuto jurídico esté sometida a tutela administrativa, podrá ser impugnado por las mismas causas de nulidad previstas en el artículo 309, mediante recurso de anulación para ante el Poder Ejecutivo, el que deberá interponerse conjuntamente y en forma subsidiaria al recurso de revocación.

Cuando el acto emane de un órgano de los Gobiernos Departamentales, se podrá impugnar con los recursos de reposición y apelación en la forma que determine la ley.

\subsection{Efectos del silencio administrativo en el Uruguay. La regla general}

En lo que interesa a este artículo, el deber de la Administración de dar respuesta a las peticiones se halla consagrado expresamente en el artículo 318 de la Constitución: 
Artículo 318. Toda autoridad administrativa está obligada a decidir sobre cualquier petición que le formule el titular de un interés legítimo en la ejecución de un determinado acto administrativo, y a resolver los recursos administrativos que se interpongan contra sus decisiones, previos los trámites que correspondan para la debida instrucción del asunto, dentro del término de ciento veinte días, a contar de la fecha de cumplimiento del último acto que ordene la ley o el reglamento aplicable. Se entenderá desechada la petición o rechazado el recurso administrativo, si la autoridad no resolviera dentro del término indicado.

La jurisprudencia ha sido contundente en subrayar esta obligación estatal, destacando que: “[El] silencio de la Administración lesiona el derecho de todo habitante de la República a conocer los fundamentos de las decisiones de la autoridad pública que lo afectan directa y personalmente — en el caso, el derecho del actor-, derecho que deriva de la forma republicana de gobierno y tiene por ello indiscutible rango constitucional (art. 72 de la Constitución). (Cf. Sent. 50/2014 y Sent. de 17/8/2018)”. "En el régimen democrático-republicano que establece la Carta, la soberanía en toda su plenitud existe radicalmente en la Nación (art. $4^{\circ}$, Constitución) y los poderes representativos la ejercen indirectamente y en su nombre (art. 82 inc. $2^{\circ}$, Constitución)". "Quien ejerce poderes delegados no puede hacerlo a su antojo, sino que debe dar las razones o fundamentos de sus actos”(4).

La cuestión del silencio también tiene tratamiento en el Reglamento de Procedimiento Administrativo Uruguayo ${ }^{(5)}$. El Decreto 500/91 señala que el procedimiento puede iniciarse a petición de persona interesada o de oficio. Una vez iniciado, se debe sustanciar el trámite y la impulsión se realiza de oficio por los órganos intervinientes, a cuyos efectos la autoridad que corresponda debe realizar las diligencias y requerir todos aquellos informes de asesoramiento que correspondan, sin perjuicio de la impulsión que puedan darle los interesados.

La autoridad competente debe pronunciarse sobre la petición que le formule el particular, pero si transcurren 150 días sin que ello ocurra, se considera que la petición o recurso ha sido rechazado (resolución denegatoria ficta). Vale destacar que, en ningún caso, el vencimiento del plazo exime a la administración del deber de pronunciarse expresamente. Si se desecha la petición —y los recursos contra el acto, ya sea de forma expresa o ficta - el particular tiene expedita la opción de hacer valer su derecho ante el órgano con competencia jurisdiccional, el Tribunal de lo Contencioso Administrativo. 
La ley 15.869 que regula el régimen de los Recursos Administrativos en Uruguay también se ocupa del caso de falta de respuesta expresa del órgano administrativo al requerimiento del particular:

Artículo 8: Las peticiones que el titular de un derecho o de un interés directo, personal y legítimo formule ante cualquier órgano administrativo, se tendrán por desechadas si al cabo de ciento cincuenta días siguientes al de la presentación no se dictó resolución expresa sobre lo pedido. El vencimiento de dicho plazo no exime al órgano de su obligación de pronunciarse expresamente sobre el fondo del asunto. La decisión expresa o ficta sobre la petición, podrá ser impugnada de conformidad con las disposiciones siguientes. Cuando el peticionario sea titular de un derecho subjetivo contra la Administración, la denegatoria expresa o ficta no obstará al ejercicio de las acciones tendientes a hacer valer aquel derecho.

De conformidad con el texto de la norma, el régimen uruguayo recepta la teoría de la ficción, considerando al silencio no solo como denegatorio, sino como un acto administrativo ficto. Esta cuestión es importante, especialmente en relación a la impugnación posterior, prevista en el artículo siguiente de la ley:

Artículo 9: La demanda de anulación deberá interponerse, so pena de caducidad, dentro de los sesenta días corridos y siguientes al de la notificación personal al recurrente o al de la publicación en el Diario Oficial del acto que ponga fin a la vía administrativa. Si hubiere recaído denegatoria ficta, el plazo correrá a partir del día siguiente a aquel en que la misma hubiera quedado configurada. Si el acto definitivo no hubiere sido notificado personalmente ni publicado en el Diario Oficial, según corresponda, se podrá interponer la demanda de anulación en cualquier momento.

Sin perjuicio de ello, la acción de nulidad caducará siempre a los dos años contados desde la fecha de la interposición de los recursos administrativos. Aunque hubiere vencido el plazo del inciso primero, la acción de nulidad podrá también ser ejercida hasta sesenta días después de la notificación personal o publicación en el Diario Oficial en su caso, de cada acto ulterior que confirme expresamente, interprete o modifique el acto recurrido o el acto que haya agotado la vía administrativa, sin poner fin al agravio. Si el Juez, de oficio o a petición de parte, declara que la demanda se presentó antes de estar agotada la vía administrativa, se suspenderán los procedimientos hasta que se 
cumpla dicho requisito. Cumplido el mismo, quedarán convalidadas las actuaciones anteriores.

La lectura de la norma puede llevar a ciertas dudas: ¿ Se produce la caducidad de la acción judicial si no se deduce la demanda dentro de los 60 días de la fecha en que la administración debió dictar el acto? Pareciera existir una cierta incompatibilidad entre la frase "si hubiere recaído denegatoria ficta, el plazo correrá a partir del día siguiente a aquel en que la misma hubiera quedado configurada” y afirmar que "si el acto definitivo no hubiere sido notificado personalmente ni publicado en el Diario Oficial, según corresponda, se podrá interponer la demanda de anulación en cualquier momento". Entendemos que la cuestión debe resolverse, como en todo caso de duda, a favor del administrado. Es decir que, en los casos de silencio de la Administración, la acción puede deducirse, aun vencido el plazo de caducidad, siempre que se la formule antes del plazo de prescripción.

A modo ilustrativo, la Corte Suprema de Justicia argentina en forma reiterada, sostuvo que en virtud del principio pro actione y el derecho constitucional de acceso a la jurisdicción, sostener el criterio que da por vencido el término (como si el acto ficticio existiera en la realidad) no hace sino premiar la actitud negligente de la Administración, por lo que el silencio debe siempre interpretarse a favor de la validez del plazo de interposición de la acción del particular.

Esta postura es también la que sostiene el Tribunal Constitucional Español al interpretar el texto (muy similar) de la ley española en materia de caducidad del plazo en casos de agotamiento de la vía por silencio: “Ante una desestimación presunta el ciudadano no puede estar obligado a recurrir en todo caso, so pretexto de convertir su inactividad en consentimiento del acto presunto, pues ello supondría imponerle un deber de diligencia que no le es exigible a la Administración... "la ley no obliga al ciudadano a recurrir un acto presunto y sí a la Administración a resolver, de forma expresa”, la solicitud o el recurso presentado por aquél... Si el silencio negativo es una institución creada para evitar los efectos paralizantes de la inactividad administrativa, es evidente que ante una resolución presunta de esta naturaleza el ciudadano no puede estar obligado a recurrir, siempre y en todo caso, so pretexto de convertir su inactividad en consentimiento con el acto presunto, exigiéndosele un deber de diligencia que no le es exigido a la Administración” (STC 188/2003, del 27 de octubre, FJ 6, en un razonamiento reafirmado luego en incontables supuestos). Es decisiva la apreciación de que "la Administración no puede verse beneficiada por el incumplimiento de su obligación de resolver expresamente 
en plazo solicitudes de los ciudadanos, deber éste que entronca con la cláusula del Estado de Derecho (art. 1.1 CE), así como con los valores que proclaman los arts. 24.1, 103.1 y 106.1 CE” (SSTC 86/1998, de 21 de abril, FJ 5; 71/2001, de 26 de marzo, FJ 4; 188/2003, de 27 de octubre, FJ 6); entre muchos otros”.

La ley 17.292 modificó la ley anterior ${ }^{(6)}$ y reguló de modo diferente el trámite de los recursos administrativos en el Uruguay, en particular el plazo para su resolución. Así, se fijó en 150 días el plazo para resolver los recursos de reposición o revocación, en 200 días cuando se interponen conjuntamente los recursos de revocación y jerárquico, de revocación y de anulación, o de reposición y apelación, y en 250 días siguientes al de la interposición conjunta de los recursos de revocación, jerárquico y de anulación, vencidos los cuales, si no se hubiere dictado resolución sobre el último recurso, se tendrá por agotada la vía administrativa. Estos plazos, en los hechos modifican y amplían el plazo de 120 días previsto en el artículo 318 de la Constitución.

La ley aclara expresamente que el vencimiento de los plazos no exime al órgano competente para resolver el recurso de que se trate (artículo 318 de la Constitución de la República). Si ésta no se produjera dentro de los treinta días siguientes al vencimiento de los plazos previstos en el inciso primero, la omisión se tendrá como presunción simple a favor de la pretensión del actor, en el momento de dictarse sentencia por el Tribunal respecto de la acción de nulidad que aquél hubiere promovido(7).

Esta presunción a favor del particular, puede resultar muy valiosa en el contencioso administrativo, donde, sin perjuicio del principio de legitimidad de los actos administrativos, se produciría una inversión de la carga de la prueba, obligando a la Administración a acreditar la validez del rechazo de la pretensión.

Alguna doctrina uruguaya (Cassinelli Muñoz, 1959) sostiene que habría tres especies dentro del género de las peticiones:

1) Las peticiones simples (que serían las previstas en el artículo 30 de la Constitución uruguaya);

2) Las peticiones calificadas (previstas en el artículo 318 de la Constitución uruguaya y el artículo 8 de la ley 15.869) realizadas por el titular de un interés legítimo y que estén referidas a la ejecución de un acto o una omisión y 
3) Los recursos administrativos propiamente dichos, similares a las peticiones calificadas, pero cuyo objeto es la impugnación de actos de la administración.

Con la recepción de la tutela administrativa y judicial efectiva de los intereses colectivos, las categorías de interés simple, interés legítimo y derecho subjetivo, tan utilizadas en la antigua doctrina administrativa han quedado superadas. Por ello, consideramos que cualquiera sea la petición, se trate de un interés simple, legítimo o un derecho subjetivo, obligan siempre a la Administración a dar una respuesta expresa y oportuna.

\subsection{Casos de silencio positivo}

Examinada la regla general del silencio como desestimación, pasaremos revista a algunas excepciones en los que el silencio tiene el efecto contrario. De acuerdo con nuestra investigación, son muy escasos los supuestos en los que el ordenamiento uruguayo confiere sentido positivo a la falta de resolución expresa. El más importante es el caso del artículo 18 de la ley 18.381 de acceso a la información pública ${ }^{(8)}$.

Esta norma jurídica permite a los interesados solicitar información respecto de asuntos de interés público. Para la respuesta a la petición, el organismo requerido está obligado a permitir el acceso o, si es posible, contestar la consulta en el momento en que sea solicitado. En caso contrario, cuenta un plazo máximo de veinte días hábiles para permitir o negar el acceso o contestar la consulta (artículo 15 de la ley 18.381). Este plazo puede prorrogarse, con razones fundadas y por escrito, por otros veinte días hábiles, si median circunstancias excepcionales. El caso de silencio positivo en la materia está expresamente consagrado en el:

Artículo 18. (Silencio positivo). El organismo requerido sólo podrá negar la expedición de la información solicitada mediante resolución motivada del jerarca del organismo que señale su carácter reservado o confidencial, indicando las disposiciones legales en que se funde. Vencido el plazo de veinte días hábiles desde la presentación de la solicitud, si no ha mediado prórroga o vencida la misma sin que exista resolución expresa notificada al interesado, éste podrá acceder a la información respectiva, considerándose falta grave la negativa de cualquier funcionario a proveérsela, de conformidad con las previsiones de la Ley N. ${ }^{\circ}$ 17.060, de 23 de diciembre de 1998, y del artículo 31 de la presente ley. 
Otro caso de silencio positivo (al menos parcial) es el previsto en el DecretoLey N. ${ }^{\circ} 14.30^{(9)}$ referido a las consultas tributarias que pueden formular los contribuyentes para la determinación de sus obligaciones ante el Fisco:

Artículo 71. (Requisitos) Quien tuviere un interés personal y directo podrá consultar al organismo recaudador correspondiente sobre la aplicación del derecho a una situación de hecho real y actual. A tal efecto deberá exponer con claridad y precisión todos los elementos constitutivos de la situación que motiva la consulta y podrá, asimismo, expresar su opinión fundada.

Artículo 72. (Efectos de su planteamiento) La presentación de la consulta no suspende el transcurso de los plazos, ni justifica el incumplimiento de las obligaciones a cargo del consultante.

Artículo 73. (Resolución) La oficina se expedirá dentro del término de noventa días.

Artículo 74. (Efectos de la resolución) La oficina estará obligada a aplicar con respecto al consultante el criterio técnico sustentado en la resolución; la modificación del mismo deberá serle notificada y sólo surtirá efecto para los hechos posteriores a dicha notificación.

Si la Administración no se hubiera expedido en el plazo, y el interesado aplica el derecho de acuerdo a su opinión fundada, las obligaciones que pudieran resultar sólo darán lugar a la aplicación de intereses, siempre que la consulta hubiere sido formulada por lo menos con noventa días de anticipación al vencimiento del plazo para el cumplimiento de la obligación respectiva.

Los casos de silencio son tan escasos, que ni siquiera en la aceptación de la renuncia de los funcionarios públicos - un supuesto muy común en el derecho comparado- opera el silencio positivo(10).

\section{El sistema argentino}

El estado argentino, a diferencia del uruguayo, se halla organizado en un sistema federal ${ }^{(11)}$, lo que determina que, a la par del sistema administrativo federal (aplicable a los procedimientos ante organismos nacionales), existen tantos ordenamientos como jurisdicciones locales (veinticuatro). En este artículo consideraremos 
solo el sistema federal, cuyas reglas generales se hallan reproducidas en los códigos provinciales, con ligeras variantes.

El deber del Estado de responder a las peticiones, que ya estaba implícito en los artículos 14 (derecho a peticionar a las autoridades) y 18 (derecho al debido proceso adjetivo) de la Constitución Nacional, ha tenido a partir de la reforma de la Constitución Nacional de 1994 un impulso adicional, con el reconocimiento de la Jerarquía Constitucional de los Tratados de Derechos Humanos en el artículo 75 inciso 22.

En especial con la norma del art. XXIV de la Declaración Americana de Derechos Humanos que expresamente reconoce, no solo el derecho a formular peticiones, sino a recibir una pronta resolución. El artículo en cuestión establece: "Artículo XXIV: Toda persona tiene derecho de presentar peticiones respetuosas a cualquiera autoridad competente, ya sea por motivo de interés general, ya de interés particular, y el de obtener pronta resolución”.

Queda claro entonces que el ciudadano no solo tiene derecho a una respuesta expresa por parte de la Administración, sino que además esta debe ser “pronta”. De acuerdo con el Diccionario de la Real Academia Española, pronto/ta es un adjetivo que significa "veloz, acelerado, ligero".

En una forma no tan expresa, pero en el mismo sentido de tutela de los derechos del particular, tanto la Declaración Universal de los Derechos Humanos, como el Pacto de San José de Costa Rica reconocen el derecho a un recurso judicial rápido y efectivo. El artículo 8 de la Convención Americana reconoce que: “Toda persona tiene derecho a un recurso efectivo ante los tribunales nacionales competentes, que la ampare contra actos que violen sus derechos fundamentales reconocidos por la constitución o por la ley”.

Es importante destacar que en el caso "Claude Reyes y otros c. Chile” (2006) la Corte Interamericana de Derechos Humanos señaló que esta garantía no obliga solo a los jueces, sino también a las autoridades administrativas que tengan funciones de adoptar decisiones que determinan derechos de los habitantes. En la misma línea, la Corte Suprema de Justicia de la Nación ha resuelto que "...El "plazo razonable" de duración del proceso al que se alude en el inciso 1, del art. 8, constituye, entonces, una garantía exigible en toda clase de proceso, difiriéndose a los jueces la casuística determinación, de si se ha configurado un retardo injustificado de la decisión..." 
De manera complementaria, el artículo 25 del mismo Pacto de San José reconoce que:

Toda persona tiene derecho a un recurso sencillo y rápido o a cualquier otro recurso efectivo ante los jueces o tribunales competentes, que la ampare contra actos que violen sus derechos fundamentales reconocidos por la Constitución, la ley o la presente Convención, aun cuando tal violación sea cometida por personas que actúen en ejercicio de sus funciones oficiales.

Las consecuencias del silencio están previstas en el Reglamento de Procedimientos Administrativos ${ }^{(12)}$ en su artículo 10:

El silencio o la ambigüedad de la Administración frente a pretensiones que requieran de ella un pronunciamiento concreto, se interpretarán como negativa. Sólo mediando disposición expresa podrá acordarse al silencio sentido positivo. Si las normas especiales no previeren un plazo determinado para el pronunciamiento, éste no podrá exceder de sesenta días. Vencido el plazo que corresponda, el interesado requerirá pronto despacho y si transcurrieren otros treinta días sin producirse dicha resolución, se considerará que hay silencio de la Administración.

La institución del silencio tiene como antecedente la Ley de Demandas contra el Estado $N^{\circ} 3952$, sancionada en 1900. Esta ley establecía en su artículo 1 que la Administración solo podía ser demandada previa denegación del reclamo administrativo. Luego, en el artículo 2 de la misma norma, se preveía el caso de silencio: "Si la resolución de la Administración demorase por más de seis meses después de iniciado el reclamo ante ella, el interesado requerirá el pronto despacho, y si transcurriesen otros tres meses sin producirse dicha resolución, la acción podrá ser llevada directamente ante los Tribunales, acreditándose el transcurso de dichos plazos”.

Como se advierte de la mera lectura de la ley, el silencio estaba previsto exclusivamente como un requisito de admisibilidad de la acción contenciosa contra el Estado, un supuesto necesario para el examen judicial de la conducta de la Administración.

\subsection{El principio general del sistema argentino}

En el derecho argentino el principio general es que, ante la falta de pronunciamiento por parte de la Administración, la omisión tiene efecto desestimatorio, salvo norma expresa en contrario. 
En la ley de procedimientos no se señalan cuáles son esas excepciones, las que resultan de normas especiales y complementarias. De todos modos, los ejemplos de silencio positivo en la legislación argentina son escasos y, además, poco utilizados. Entre los casos de silencio estimatorio, cabe citar la aceptación tácita de la renuncia de los funcionarios públicos nacionales, si no se produce su rechazo dentro de los 30 días de presentada ${ }^{(13)}$; el caso de la autorización para realizar transporte aéreo de pasajeros no regulares (charters) $^{(14)}$, la falta de pronunciamiento del Tribunal de Defensa de la Competencia sobre proyectos de concentración económica y operaciones de control de empresas ${ }^{(15)}$ la importación de gas natural ${ }^{(16)}$ y los proyectos de concentración económica(17).

¿Cuál es el plazo dentro del cual la Administración debe resolver la pretensión del particular? La ley de procedimientos establece un plazo supletorio general de 60 (sesenta) días. En los demás casos, se debe estar a los plazos fijados en las leyes especiales, que puede ser inferior o superior al plazo supletorio, por ejemplo, el de 30 (treinta) días para resolver el recurso jerárquico, o el de 5 (cinco) días para emitir un dictamen jurídico ${ }^{(18)}$.

Cuando se trata de una petición o reclamo, se exige la denuncia de la mora administrativa y el transcurso de un segundo período de inactividad de 30 días (art. 10 de la ley 19.549 o de 45 días en la vía reclamatoria (art. 31 de la misma ley). Por el contrario, cuando se ha deducido un recurso administrativo, el silencio se produce de forma automática, una vez que ha transcurrido el plazo para resolver (por lo general, 30 días).

\subsection{Efectos del silencio en el sistema argentino}

El silencio de la Administración, en las condiciones previstas en el artículo 10 del Decreto Ley 19549, permite al particular considerar como denegado su pedido. Es importante señalar que esta posibilidad es un derecho del particular peticionante, no de la Administración, ni de terceros, aun cuando tengan interés en el procedimiento (Tenreyro, 2011, pág. 186).

En relación al funcionario, la falta de pronunciamiento expreso puede generar responsabilidad civil, penal y administrativa. En lo que respecta al particular, éste puede adoptar varias alternativas para intentar vencer la inactividad del ente público. Estas vías son la de promover un pedido de pronto despacho administrativo, deducir una acción de amparo por mora o iniciar una acción contenciosa administrativa. A continuación, analizaremos brevemente esas alternativas. 


\section{a) Pronto despacho administrativo}

El pronto despacho es una técnica prevista en la ley de procedimientos administrativos por la cual, quien es parte en el trámite administrativo, formula un urgimiento (pedido de pronto despacho) para que el ente resuelva la cuestión de modo expreso. Este pedido cuenta con un apercibimiento expreso: si la Administración no dicta el acto en el plazo de 30 días, se considera denegado y queda expedita la vía judicial. El pronto despacho se realiza por escrito, sin otras formalidades que las que corresponde a toda otra presentación a la Administración y permite un rápido agotamiento de la vía administrativa.

\section{b) Amparo por mora}

El amparo por mora es una acción dirigida a exigir al órgano moroso que explique las razones de su inactividad (formal). Algunos autores entienden que el amparo por mora tiene una raíz común con el amparo genérico del artículo 43 de la Constitución argentina (Sagües, 2004) y que emana del derecho al debido proceso (artículo 18 de la Constitución Nacional), ya que la inactividad o morosidad administrativa virtualmente opera como denegación de justicia en sentido amplio (Dromi, 2009), especialmente cuando el agotamiento de la vía administrativa constituye requisito para poder acceder a la justicia contencioso administrativa. La acción de amparo por mora está prevista en el artículo 28 del Decreto Ley 19549 que establece:

El que fuere parte en un expediente administrativo podrá solicitar judicialmente se libre orden de pronto despacho. Dicha orden será procedente cuando la autoridad administrativa hubiere dejado vencer los plazos fijados y en caso de no existir éstos, si hubiere transcurrido un plazo que excediere de lo razonable sin emitir el dictamen o la resolución de mero trámite o de fondo que requiera el interesado. Presentado el petitorio, el juez se expedirá sobre su procedencia, teniendo en cuenta las circunstancias del caso, y si lo estimare pertinente requerirá a la autoridad administrativa interviniente que, en el plazo que le fije, informe sobre las causas de la demora aducida. La decisión del juez será inapelable. Contestado el requerimiento o vencido el plazo sin que se lo hubiere evacuado, se resolverá lo pertinente acerca de la mora, librando la orden si correspondiere para que la autoridad administrativa responsable despache las actuaciones en el plazo prudencial que se establezca según la naturaleza y complejidad del dictamen o trámites pendientes. 
El proceso de amparo por mora — de carácter sumarísimo- concluye con una sentencia que declara la existencia o no de mora, y en este último caso, la condena a la Administración a dictar el acto, también bajo apercibimiento de habilitar la vía judicial. La vía del amparo por mora es sencilla, rápida y económica.

\section{c) Acción contenciosa administrativa}

La última alternativa del particular ante el silencio es la de considerar agotada la vía administrativa por silencio, una vez vencido el plazo legal para resolver, y deducir la acción contenciosa administrativa. En este caso, la acción tendrá por objeto el reconocimiento del derecho desconocido, la nulidad de un acto (previo al silencio) y/o la reparación de los daños causados por la Administración.

Más allá de algunas vacilaciones de la jurisprudencia y de algunas interpretaciones restrictivas, en los casos de silencio de la Administración no corre plazo de caducidad para deducir la acción contenciosa administrativa. El fundamento es que el particular no puede, ante la conducta ilegítima de la Administración de no resolver el pedido, verse en una situación peor que aquel a quien se le ha denegado de modo expreso, como ya hemos sostenido más arriba al analizar la caducidad de la acción en el caso uruguayo.

\section{Similitudes y diferencias de ambos sistemas}

Habiendo expuesto el sistema argentino y el sistema uruguayo de regulación del silencio administrativo, corresponde ahora analizar las principales similitudes y diferencias de ambos ordenamientos.

\subsection{Similitudes}

a. Reconocimiento de la obligación de la Administración de resolver y del derecho del ciudadano a una decisión expresa y fundada.

En el caso de Uruguay la obligación de resolver tiene rango constitucional (art. 318 de la Constitución uruguaya). En el caso de Argentina, la obligación de expedirse sobre el reclamo es supranacional (convencional con jerarquía constitucional en Argentina, artículo 75 inciso 22 de la Constitución) y legal. 
b. Principio del silencio como desestimatorio de la pretensión, con limitadas excepciones

Ambos ordenamientos consagran el principio del silencio como desestimación de la petición o recurso. En ambos derechos, el principio no es absoluto, sino que admite excepciones, las que serán consideradas en la sección de diferencias.

\subsection{Diferencias}

a. Solo para el caso de silencio (Uruguay); casos de silencio o ambigüedad (Argentina)

En el caso uruguayo solo se contempla de modo expreso el caso de silencio. La ley argentina comprende no solo los casos de silencio (falta de respuesta absoluta) sino también los de ambigüedad (falta de respuesta completa o clara).

b. Rango constitucional de la regla de silencio negativo (Uruguay), rango exclusivamente legal del silencio negativo en Argentina

Esta diferencia en la jerarquía de las normas que consagran el principio incide directamente en la posibilidad de modificación: En el caso uruguayo solo puede realizarse a través de una reforma constitucional, con todos los inconvenientes que de ello se derivan. En Argentina, la cuestión puede ser modificada con relativa facilidad, con el dictado de una nueva ley que modifique o flexibilice el principio.

c. Mayor cantidad de excepciones (casos de silencio positivo) en Argentina

Como hemos visto en el detalle del sistema argentino, existen más casos de silencio positivo, a diferencia de las casi nulas excepciones en Uruguay.

\section{d. Plazo para que se produzca el silencio}

En Uruguay deben transcurrir 120/150 días si es una petición o recurso, 200 si se ha interpuesto también el recurso jerárquico o de apelación y 250 si son tres los recursos. En Argentina, basta con el vencimiento del plazo para resolver: solo 30 días en los recursos o 45 días en caso de reclamos (en algunos casos se requiere intimación). 


\section{e. Instrumentos para el cese de la inactividad}

Comparando ambos sistemas, en Argentina existen más y mejores instrumentos —al menos en teoría - : pronto despacho, amparo por mora, y agotamiento de la vía administrativa por silencio. En Uruguay solo están previstas la acción de amparo (Ley N. ${ }^{\circ}$ 16.011) contra la omisión de resolver ${ }^{(19)}$ y el agotamiento de la vía administrativa.

\section{f. Posición del particular en el proceso posterior}

En el Uruguay, el silencio de la Administración genera una presunción simple a favor de la pretensión del administrado cuando a posteriori se impugna lo actuado por la Administración en sede judicial. Esta presunción no existe en el derecho argentino, donde la carga probatoria no posee diferencia del caso del pronunciamiento expreso.

\section{Reflexiones finales}

En los capítulos anteriores se expusieron críticamente los sistemas argentino y uruguayo en relación al silencio administrativo. En este último capítulo se exponen las conclusiones que resultan de la comparación de ambos sistemas.

El silencio de la Administración es una institución muy significativa dentro del procedimiento administrativo, ya que permite una solución, al menos parcial, a la falta de actividad formal de los órganos públicos. Esta falta de respuesta puede tener como consecuencia la estimación o desestimación de la petición. La elección de una u otra alternativa es materia de apreciación de normas de rango legal o superior, para la mejor defensa de los derechos de los ciudadanos.

En tal sentido, es importante señalar que cualquiera sea la decisión constitucional o legislativa que se adopte, el instituto del silencio administrativo - que parte de un incumplimiento del deber de resolver del Estado- debe ser siempre interpretado en base al principio pro homine, es decir, en el sentido más favorable al particular. El principio se halla consagrado en el artículo 5 del Pacto Internacional de Derechos Civiles y Políticos y el artículo 18 del Convenio Europeo para la Protección de los Derechos Humanos y de las Libertades Fundamentales. Por lo tanto, siempre habrá de preferirse la interpretación que resulte menos restrictiva de los derechos reconocidos en ellos. Así cuando unas normas ofrezcan mayor protección, 
estas habrán de primar, de la misma manera que siempre habrá de preferirse en la interpretación la hermenéutica que resulte menos restrictiva para la aplicación del derecho fundamental comprometido. La Comisión Interamericana de Derechos Humanos define el principio pro homine expresando que en materia de reconocimiento de derechos, se debe estar a la norma más amplia y a la interpretación más extensiva e, inversamente, a la norma y a la interpretación más restringida en materia de limitación de derechos. ${ }^{(20)}$ La Corte Interamericana de Derechos Humanos ha identificado al principio pro homine como un principio de interpretación extensiva de los derechos humanos y restrictiva de sus limitaciones ${ }^{(21)}$.

Por eso, en ningún caso debe admitirse la pérdida del derecho del particular como consecuencia de la falta de pronunciamiento expreso de la Administración, salvo los casos en que el ordenamiento impone una carga al particular en relación al impulso del trámite. La importancia del criterio interpretativo pro homine ha sido destacado por la Doctrina argentina como una pauta hermenéutica básica del sistema de derechos humanos (Sagüés, 2002) (Pinto, 1997). También la Corte Suprema de Justicia de la Nación argentina ha reconocido la plena vigencia de este principio en materia de derechos fundamentales en los casos "Cardozo"(22), "Madorrán”(23) y "Alvarez"(24), entre otros.

No quisiéramos concluir este trabajo sin señalar el impacto que las nuevas tecnologías producen en la gestión administrativa de los Estados. Es muy probable que el movimiento tendiente a una incorporación masiva de nuevas tecnologías a la gestión pública conduzca a más casos de silencio positivo o de respuesta automatizada. En el caso de Argentina, este proceso se ha iniciado con fuerza en los últimos 5 años ${ }^{(25)}$ y parece destinado a lograr no solo el destierro del papel como soporte de los expedientes, sino a un cambio total de paradigma, donde el ciudadano adquiera mayor relevancia y autonomía. También Uruguay ha iniciado el proceso de despapelización (Delpiazzo, 2010) a partir de la entrada en vigencia de la ley 17.243 en 2000. Solo a través del sitio Portal del Estado Uruguayo, hoy es posible realizar miles de trámites totalmente en línea. En este esquema, es plausible suponer que, en línea con la tendencia mundial, en ambos ordenamientos sean cada vez más los casos en que se otorgue al silencio de la Administración un sentido positivo, especialmente de autorización o permiso. 


\section{Referencias}

Bielsa, R. (1942). Principios de Derecho Administrativo. Buenos Aires: UNL.

Cajarville Peluffo, J. P. (2014). Breve presentación de la jurisdicción contencioso administrativa uruguaya. Revista de la Facultad de Derecho (23), 123-144.

Cassinelli Muñoz, H. (1959). Obligación de decidir y acto administrativo ficto en la Constitución. DJA, 148.

Delpiazzo, C. E. (2010). Noción y regulación del procedimiento y del acto administrativo electrónico. Estudios de Derecho Administrativo 1, 79-108.

Dromi, R. (2009). Derecho Administrativo 12 ed. act. Buenos Aires: Ciudad Argentina-Hispania Libros.

Gelli, M. A. (2008). Constitución de la Nación Argentina. Buenos Aires: La Ley.

Gordillo, A. (2016). Tratado de Derecho Administrativo y obras selectas. Buenos Aires: FDA.

Gordillo, A. D. (2010). Procedimiento Administrativo. Decreto Ley 19.549/1972 y normas reglamentarias - Ley de Procedimientos Administrativos de la Ciudad Autónoma de Buenos Aires Comentados y concordados 2a. ed. Buenos Aires: Abeledo Perrot.

Gusmán, A. S. (2014). Juicio de Amparo por mora de la Administración. Buenos Aires: Hammurabbi.

Lima, F. (2009). El silencio de la Administración y la habilitación de la instancia judicial. http://www.gordillo.com

Nieto García, A. (1962). La inactividad material de la Administración y el recurso contencioso administrativo. $R A P(80), 75-126$.

Perrino, P. E. (2003). El derecho a la tutela judicial efectiva y el acceso a la jurisdicción contencioso administrativa. Revista de Derecho Público, 257/294. 
Peyrano, J. (1993). El Proceso Atípico. Buenos Aires: Universidad.

Pinto, M. (1997). El principio pro homine. Criterios de hermenéutica y pautas para la regulación de los derechos humanos. En M. Abregú, La aplicación de los tratados sobre derechos humanos por. Buenos Aires: CELS-Editores del Puerto.

Rodríguez Arana, J. S. (2009). Derecho Administrativo Español. La Coruña: Netbiblo.

Sagüés, N. P. (2002). La interpretación de los derechos humanos en las jurisdicciones nacional e internacional. En J. Palomino, Derechos humanos y Constitución en Iberoamérica (Libro-homenaje a Germán J. Bidart Campos). Lima: Instituto Iberoamericano de Derecho Constitucional.

Sagües, N. P. (2004). Derecho Procesal Constitucional. Buenos Aires: Astrea.

Tenreyro, P. (2011). Técnicas de tutela frente a la inactividad administrativa. Córdoba: Advocatus.

\section{Notas}

${ }^{1}$ Constitución de la República Oriental del Uruguay, Artículo 30: “Todo habitante tiene derecho de petición para ante todas y cualesquiera autoridades de la República”.

${ }^{2}$ Constitución de la República Argentina, Artículo 14: “Todos los habitantes de la Nación gozan de los siguientes derechos conforme a las leyes que reglamenten su ejercicio; a saber: de trabajar y ejercer toda industria lícita; de navegar y comerciar; de peticionar a las autoridades...”.

${ }^{3}$ En el caso de estas últimas, las demandas contra el Estado tramitan ante el fuero ordinario.

${ }^{4}$ Tribunal Apelaciones Civil $6^{\circ}$ Turno, Sentencia del 11/09/19, en autos "AA c/ Ministerio de Salud Pública y otros/Amparo", IUE 2-39401/2019; entre muchos otros fallos allí referidos.

${ }^{5}$ Decreto del Poder Ejecutivo N 500 del 27 de septiembre de 1991. 
${ }^{6}$ Publicada en el B. O el 29/01/01.

${ }^{7}$ Artículo 6: Vencido el plazo de ciento cincuenta días o el de trescientos, en su caso, se deberán franquear, automáticamente, los recursos subsidiariamente interpuestos reputándose fictamente confirmado el acto impugnado. El vencimiento de los plazos a que se refiere el inciso anterior no exime al órgano competente para resolver el recurso de que se trate, de su obligación de dictar resolución sobre el mismo (artículo 318 de la Constitución). Si ésta no se produjera dentro de los sesenta días siguientes a aquel en que se configuró la denegatoria ficta, la omisión se tendrá como presunción simple a favor de la pretensión del administrado en el momento de dictarse sentencia por el Tribunal, para el caso que se promoviere acción de nulidad.

${ }^{8}$ Sancionada el 7/10/08.

${ }^{9}$ Publicada B.O. 6/12/74.

${ }^{10}$ Artículo 83. (Renuncia) La renuncia puede ser expresa o tácita, el primer caso se configura cuando la solicitud del funcionario sea aceptada por el jerarca del Inciso o quien haga sus veces, el segundo caso se configura cumplidos tres días hábiles continuos en que el funcionario faltare a sus tareas sin aviso e intimado por medio fehaciente al reintegro bajo apercibimiento no se presente a trabajar al día laborable inmediatamente posterior a la intimación. La misma se realizará en el domicilio denunciado por el funcionario en su legajo. Ley N. ${ }^{\circ} 19.121$ Estatuto del Funcionario Público de la Administración Central; Publicada D.O. 28/08/13.

${ }^{11}$ Constitución de la Nación Argentina, Artículo $1^{\circ}$. La Nación Argentina adopta para su gobierno la forma representativa republicana federal, según la establece la presente Constitución.

\section{${ }^{12}$ Decreto Ley 19.549/72.}

${ }^{13}$ Ley Marco de Regulación del Empleo Público ( $\mathrm{N}^{\circ}$ 25.164) Artículo 22 del Anexo: La renuncia es el derecho a concluir la relación de empleo produciéndose la baja automática del agente a los treinta (30) días corridos de su presentación, si con anterioridad no hubiera sido aceptada por autoridad competente. La aceptación de la renuncia podrá ser dejada en suspenso por un término no mayor de ciento ochenta (180) días corridos si al momento de presentar la renuncia se encontrara involucrado en una investigación sumarial. 
${ }^{14}$ Decreto del Poder Ejecutivo Nacional N 1470/97, Normas de aplicación a las que deberán ajustarse las empresas aéreas autorizadas, nacionales y extranjeras, para la realización de servicios no regulares de transporte aéreo de pasajeros, denominados Charters; Artículo 4: Dentro de los diez (10) días hábiles de efectuada la presentación la autoridad deberá expedirse respecto de la solicitud. En caso de no existir pronunciamiento, se considerará automáticamente concedido el permiso.

${ }^{15}$ Ley 25.156 de Defensa de la Competencia; Artículo 13: En todos los casos sometidos a la notificación prevista en este capítulo, el Tribunal por resolución fundada, deberá decidir dentro de los cuarenta y cinco (45) días de presentada la solicitud y documentación respectiva:

a) Autorizar la operación;

b) Subordinar el acto al cumplimiento de las condiciones que el mismo Tribunal establezca;

c) Denegar la autorización.

La solicitud de documentación adicional deberá efectuarse en un único acto por etapa, que suspenderá el cómputo del plazo por una sola vez durante su transcurso, salvo que fuere incompleta. (Párrafo incorporado por art. $4^{\circ}$ del Decreto N 396/2001 B.O. 5/4/2001.- Vigencia a partir del 9/4/2001).

Artículo 14: Transcurrido el plazo previsto en el artículo anterior sin mediar resolución al respecto, la operación se tendrá por autorizada tácitamente. La autorización tácita producirá en todos los casos los mismos efectos legales que la autorización expresa.

${ }^{16}$ Ley 24.076, artículo $3^{\circ}$.- Quedan autorizadas las importaciones de gas natural sin necesidad de aprobación previa. Las exportaciones de gas natural deberán, en cada caso, ser autorizadas por el Poder Ejecutivo Nacional, dentro del plazo de noventa (90) días de recibida la solicitud, en la medida que no se afecte el abastecimiento interno. El silencio, en tal caso, implicará conformidad. Los importadores y exportadores, deberán remitir al Ente Nacional Regulador del Gas una copia de los respectivos contratos. 
${ }^{17}$ Ley 25.156 de Defensa de la Competencia, artículo 14. - Transcurrido el plazo previsto en el artículo anterior sin mediar resolución al respecto, la operación se tendrá por autorizada tácitamente. La autorización tácita producirá en todos los casos los mismos efectos legales que la autorización expresa.

${ }^{18}$ Decreto 1759/72, Artículo 26. Responsabilidad de la tramitación. La elaboración de meros informes, contestación de comunicaciones oficiales y todo otro diligenciamiento de documentación, relativos a la sustanciación de expedientes, cuando no estuviera establecido otro término, serán realizados en un plazo máximo de cinco (5) días hábiles administrativos. Este plazo máximo podrá ser ampliado por el superior jerárquico del responsable primario cuando la complejidad de los asuntos a tratarse lo justifique.

Los titulares de las unidades administrativas y el personal que tuviese a su cargo la resolución o el despacho de los asuntos, serán responsables directos de su tramitación y adoptarán las medidas oportunas para remover los obstáculos que impidan, dificulten o retrasen el ejercicio pleno de los derechos de los interesados o el respeto a sus intereses legítimos, disponiendo lo necesario para evitar y eliminar toda anormalidad en la tramitación de procedimientos. El personal que tenga a su cargo el despacho de los asuntos, así como los titulares de los órganos administrativos competentes para instruir y resolver son directamente responsables, en el ámbito de sus competencias, del cumplimiento de la obligación legal de dictar resolución expresa en plazo. El incumplimiento de dicha obligación dará lugar a responsabilidad disciplinaria, sin perjuicio de la que hubiere lugar de acuerdo con la normativa aplicable.

${ }^{19}$ Publicada B.O. el 29/12/88.

${ }^{20}$ Comisión Interamericana de Derechos Humanos, Informe 35/07 en autos "Jorge, José y Dante Peirano Basso c/ República Oriental del Uruguay”, del 1 de mayo de 2007.

${ }^{21}$ Corte Interamericana de Derechos Humanos, Opinión Consultiva 5/85.

${ }^{22}$ Fallo del 20 de junio de 2006.

${ }^{23}$ Fallo del 3 de mayo de 2007.

${ }^{24}$ Fallo del 7 de diciembre de 2010. 
${ }^{25}$ Ley 27.446 Simplificación y Desburocratización de la Administración Pública Nacional; Decreto 434/2016 "Plan Nacional de Modernización del Estado" para la orientación de la acción estatal hacia el ciudadano (1/3/2016); Decreto 561/2016 Uso obligatorio de GDE como único sistema para la tramitación electrónica de todas las actuaciones y expedientes del Sector Público Nacional y baja del Sistema COMDOC y otros sistemas similares (6/4/2016); Decreto 1273/2016 Simplificación de acceso a servicios de organismos públicos, intercambio obligatorio de la información pública de sistemas y bases de datos del SPN (“Interoperabilidad"), y designación de la Secretaría de Modernización Administrativa (SMA) para dictar normas técnicas y operativas (19/12/2016); Decreto 891/2017 Simplificación normativa y funcional en el dictado de normativa y regulaciones del SPN, presunción de buena fe del ciudadano, fomento de la intercambio de información entre el Gobierno Nacional, las provincias y CABA, presunción de respuesta positiva al ciudadano ante el silencio de la Administración frente a sus solicitudes, y creación de nuevos Registros electrónicos y gratuitos con autorización previa del Jefe De Gabinete De Ministros para la Administración centralizada, o del Poder Ejecutivo Nacional para resto de la Administración (1/11/2017); Decreto 894/2017 Reglamento de Procedimientos Administrativos. 